\title{
MET-2, a SETDB1 family methyltransferase, coordinates embryo events through distinct histone $\mathrm{H} 3$ methylation states.
}

Beste Mutlu¹, Huei-Mei Chen ${ }^{1}$, David H. Hall², Susan E. Mango ${ }^{1,3}$.

\section{Affiliations:}

${ }^{1}$ Department of Molecular and Cellular Biology, Harvard University, Cambridge, MA

${ }^{2}$ Center for C. elegans Anatomy, Albert Einstein College of Medicine, Bronx, NY

${ }^{3}$ current address: Biozentrum, University of Basel, 4056 Basel, Switzerland

*Correspondence to: smango@mcb.harvard.edu

Keywords: SETDB1, pluripotency, heterochromatin, embryogenesis, met-2 


\section{SUMMARY STATEMENT}

During early embryogenesis, heterochromatin formation and loss of developmental plasticity are coordinately regulated by distinct Histone H3 Lysine 9 (H3K9) methylation states, by the methyltransferase MET-2.

\section{ABSTRACT}

During the first hours of embryogenesis, formation of higher-order heterochromatin coincides with the loss of developmental potential. Here we examine the relationship between these two processes, and we probe the determinants that contribute to their onset. Mutations that disrupt histone $\mathrm{H} 3$ lysine 9 (H3K9) methyltransferases reveal that the methyltransferase MET-2 helps terminate developmental plasticity, likely through mono- and di- methylation of $\mathrm{H} 3 \mathrm{~K} 9$ (me1/me2), and promotes heterochromatin formation, likely through $\mathrm{H} 3 \mathrm{~K} 9 \mathrm{me}$. We examine how MET-2 is regulated and find that methylated H3K9 appears gradually and depends on the accumulated time of embryogenesis. H3K9me is independent of zygotic genome activation or cell counting. These data reveal how central events are synchronized during embryogenesis and distinguish distinct roles for different $\mathrm{H} 3 \mathrm{~K} 9$ methylation states. 


\section{INTRODUCTION}

Upon fertilization, embryos initiate developmental events to control cell division, pluripotency, differentiation, reorganization of the nucleus, onset of transcription and repositioning of cells into germ layers that ultimately generate organs and tissues. These processes are coordinated in time and space. In $C$. elegans, for example, the reorganization of cells during gastrulation coincides with loss of developmental plasticity, the formation of heterochromatin and a surge of transcription. While the timing of these events has been defined (Mango, 2009; Mutlu et al., 2018; Robertson et al., 2004; Seydoux and Fire, 1994; Sulston et al., 1983; Yuzyuk et al., 2009), little is known about the processes that regulate the timing or synchronization of different events (Detwiler et al., 2001; Mutlu et al., 2018; Yuzyuk et al., 2009). To begin to address this issue, we have examined whether early embryonic events are contingent upon each other or regulated independently.

C. elegans embryos, like other those of other animals, are born pluripotent and lack higher-order heterochromatin, the portion of the genome that carries repetitive DNA and is less transcriptionally active (Mutlu et al., 2018). As embryos transition towards gastrulation, they lose developmental potential and generate heterochromatin (Mutlu et al., 2018). In cultured mammalian cells, the enzymes that promote heterochromatin formation also inhibit reprogramming into embryonic stem cells, suggesting a possible link between these processes (Gaspar-Maia et al., 2009; Kang, 2014; Soufi et al., 2012; Zaret and Mango, 2016). For example, in mammals, the H3K9 methyltransferase SETDB1 both promotes heterochromatin formation and dampens reprogramming efficiency (Becker et al., 2015). However, SETDB1 is responsible for multiple H3K9 
modifications, making it difficult to determine whether different methylated states have distinct roles. Conversely, in many mammals, multiple enzymes contribute to a given modification, which complicates studying the function of a single histone modification. We use $C$. elegans, which enabled us to dissect the roles of different H3K9 methylated states. C. elegans MET-2 is homologous to SETDB1 (Andersen and Horvitz, 2007; Poulin et al., 2005) and is responsible for virtually all embryonic H3K9me1/me2, but has only partial effects on H3K9me3; SET-25 is necessary for virtually all H3K9me3, but not H3K9me1/me2 (Towbin et al., 2012). The separation of enzymatic activities provides an opportunity to determine which modifications govern which processes. Studying an intact animal also enables us to establish the temporal order of events in relation to developmental milestones.

The formation of heterochromatin during $C$. elegans embryogenesis depends on MET-2 (Mutlu et al., 2018). Early embryos have almost no H3K9me2 and low levels of H3K9me1 and H3K9me3. By transmission electron microscopy, they lack heterochromatin. As embryos develop, MET-2 becomes enriched in the nucleus, promotes an increase in all three methylated forms of histone $\mathrm{H} 3$ and generates heterochromatin (Mutlu et al., 2018). It is unknown if MET-2 also regulates developmental potential, nor are the separate roles of mono, di and tri H3K9me understood. Here we examine these different roles by studying MET-2 and SET-25, and we investigate how MET-2 and H3K9 methylation are regulated in early embryos. 


\section{RESULTS}

\section{MET-2 promotes loss of plasticity.}

We took advantage of the Cell Fate Challenge assay (CFC) (Horner et al., 1998; Mango, 2009) to test the importance of met-2 for developmental plasticity (Figure 1). C. elegans embryos develop within 14 hours, with initiation of zygotic transcription at the 4-cell stage and gastrulation at the 28-cell stage (Schauer and Wood, 1990; Seydoux and Fire, 1994; Sulston et al., 1983). Prior to gastrulation, cells are developmentally plastic, and their normal pattern of development can be reprogrammed by ectopic expression of selector genes, but this flexibility is lost during gastrulation (Djabrayan et al., 2012; Fukushige and Krause, 2005; Gilleard and McGhee, 2001; Horner et al., 1998; Mango, 2009; Priess and Thomson, 1987; Sulston et al., 1983; Wood, 1991; Zhu et al., 1998).

Embryos were induced to alter their cell identity and acquire muscle fate by ectopic expression of $h / h-1 / M y o D$ under control of the heat-shock promoter (HS::hlh-1; (Fukushige and Krause, 2005)). We focused on the 80-100-cell stage (mid-gastrulation), when wild-type embryos have an intermediate response to the CFC assay, thereby providing a sensitive assay (Figure 1A-B). In addition, H3K9me2 is readily visible at this developmental stage in wild-type embryos but absent from met-2 mutants (Mutlu et al., 2018). The foregut marker PHA-4 was used to identify cells that retained their endogenous identity and resisted exogenous $\mathrm{HLH}-1$, and muscle paramyosin was used to track conversion to muscle fate (Horner et al., 1998; Yuzyuk et al., 2009). We concentrated on endogenous fate markers because exogenous reporters can sometimes lead to spurious expression or regulation (Jiao et al., 2018; Mango, 2007). As a control, 
we examined h/h-1 mRNA expression before and after heat shock and observed no difference in induction between wild-type and mutant embryos (Figure 1D).

When challenged with HS::hlh-1, 35\% of 100-cell-stage wild-type embryos converted to muscle fate completely, consistent with previous studies (Fukushige and Krause, 2005; Mango, 2009; Yuzyuk et al., 2009). In met-2 mutants, 54\% of embryos responded to HS::hlh-1 with a complete cell-fate transformation (Figure 1C, 100-cell stage, $n=4,>100$ embryos each, $p=0.008)$. This result suggests that, normally, met-2 promotes loss of plasticity during early gastrulation. By the $\sim 200$ cell stage, none of the wild-type or met-2 mutant embryos remained fully plastic (Figure 1C). Moreover, both wild-type and met-2 mutant embryos had a similar number of cells that resisted changing fate, indicating that met-2 mutants eventually terminate plasticity (Supplementary Figure 1). The data reveal that met-2 restricts developmental plasticity during gastrulation but is not absolutely required. The partial requirement for met-2 may reflect that other regulators also control developmental plasticity in the embryo (Djabrayan et al., 2012; Joshi et al., 2010; Yuzyuk et al., 2009).

H3K9me1/me2 exist in the embryo and, in addition, are used to produce H3K9me3 by SET-25 (Towbin et al., 2012). We wondered whether either the plasticity or the heterochromatin phenotype of met-2 could be explained by its role in generating H3K9me3. First, we examined developmental plasticity with the CFC assay. Inactivation of set-25 lead to the opposite result as met-2: only $20 \%$ of set-25 embryos were developmentally plastic, about half of wild-type (Figure 1C, $n=3$ experiments, >60 embryos each, $\mathrm{p}=0.011)$. This result demonstrated that $\mathrm{H} 3 \mathrm{~K} 9 \mathrm{me} 3$ was not required to terminate plasticity during gastrulation. Rather, developmental plasticity correlated with 
the level of $\mathrm{H} 3 \mathrm{~K} 9 \mathrm{me} 2$, which is low in met-2 mutants and high in set-25 mutants relative to wild-type (Supplementary Figure 2).

To test the importance of H3K9me2, we examined met-2; set-25 double mutants, which lack mono, di and tri H3K9me (Garrigues et al., 2014; Towbin et al., 2012). The double mutants had prolonged plasticity (Figure 1C, $n=2,30$ embryos each, $p=0.045$ ), revealing that the reduced plasticity of set-25 mutants required wild-type met-2 activity. A simple hypothesis to explain these results is that $\mathrm{H} 3 \mathrm{~K} 9 \mathrm{me} 1$ and/or $\mathrm{H} 3 \mathrm{~K} 9 \mathrm{me} 2$ is required to terminate developmental plasticity but $\mathrm{H} 3 \mathrm{~K} 9 \mathrm{me} 3$ is not. To gain insight into genes regulated by $\mathrm{H} 3 \mathrm{~K} 9 \mathrm{me} 1$ and $\mathrm{H} 2 \mathrm{~K} 9 \mathrm{me} 2$, we examined modENCODE data for genes bearing either of these marks. Among genes with peaks of H3K9me1, there was enrichment for GO terms "intracellular signaling cascade," and regulation of "developmental process" and "growth" (Figure 1E). For H3K9me2, there was enrichment for "cell-fate determination" and "embryonic pattern specification," which included genes expressed in the pre-gastrula embryo (e.g. par-1, par-4, mbk-2 and others). These GO terms were not enriched for $\mathrm{H} 3 \mathrm{~K} 9 \mathrm{me} 3$, possibly explaining the distinct phenotypes of met2 vs. set-25.

Figure 1. MET-2 promotes loss of developmental plasticity at mid-gastrulation. A. Cell Fate Challenge Assay (CFCA). Muscle fate regulator $h / h-1 / M y o D$ is induced in somatic cells. Terminally differentiated embryos stained for induced or endogenous fate markers (muscle paramyosin, red, or foregut PHA-4, green, respectively (Fukushige and Krause, 2005; Horner et al., 1998)).

B. Terminally differentiated embryos. Arrowheads depict cells lacking paramyosin, some of which express PHA-4. Scale bar, $5 \mu \mathrm{m}$.

C. Percentage of wild-type $(n=109)$ vs. met- $2(n=136)$ or wild-type $(n=64)$ vs. set-25 (84) or wild-type $(\mathrm{n}=31)$ vs. met-2; set-25 $(\mathrm{n}=38)$ embryos scored as developmentally plastic based on absent PHA-4 and ubiquitous paramyosin. Note that MET-2 promotes loss of plasticity, while SET-25 prevents it. 
D. hlh-1/MyoD mRNA levels normalized to eft-3 in wild-type or mutant embryos, with $(+\mathrm{HS})$ or without $(-\mathrm{HS})$ heat-shock induction. CFCA results are not due to differential induction of hlh-1 in wild-type vs. mutants.

E. GO Term Analysis for genes enriched for H3K9 methylation. Genes associated with $\mathrm{H} 3 \mathrm{~K} 9 \mathrm{me} 2$ are involved in regulating plasticity, whereas H3K9me1 and H3K9me3 are not.

Figure 1

A
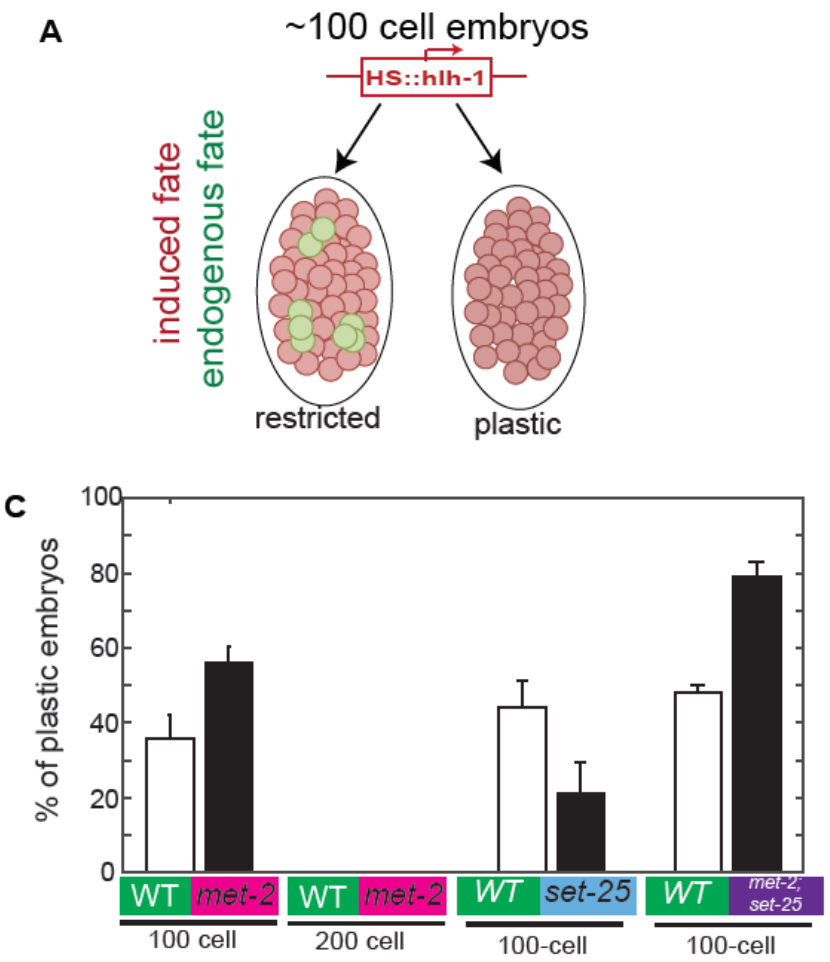

D

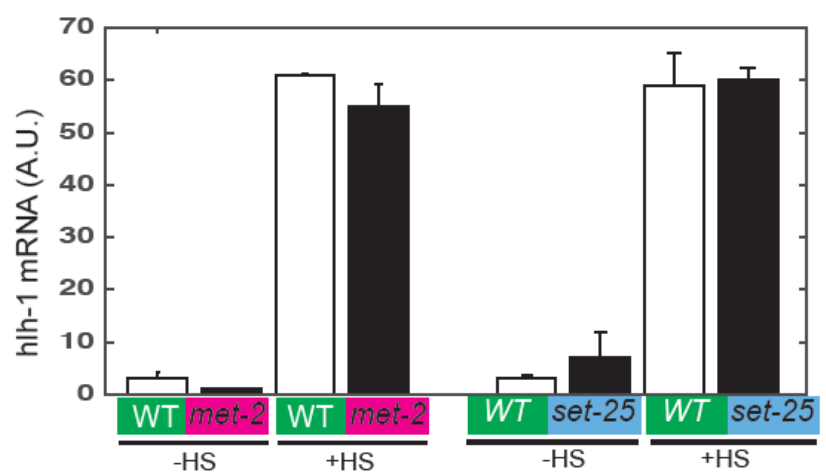

B

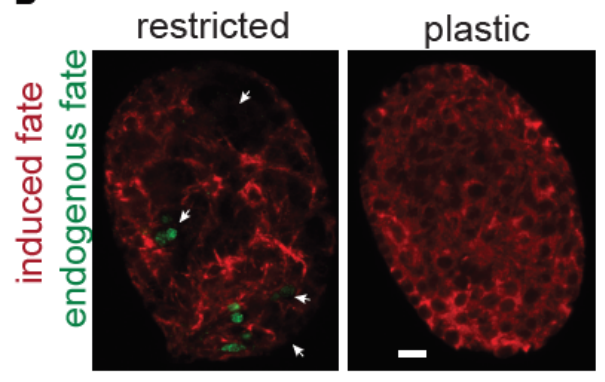

E intracellular signaling cascade multicellular organism reproduction positive regulation of developmental process $\quad 0.000651$ positive regulation of growth $2.05 \mathrm{E}-05$ positive regulation of vulval development $\quad 0.000701$ protein amino acid phosphorylation $\quad 0.000247$ regulation of post-embryonic development $\quad 0.000175$ regulation of transcription $\quad 0.000723$ small GTPase mediated signal transduction $\quad 0.000303$ synaptic transmission, cholinergic $\quad 0.00069$ H3K9me2 GO term p-value cell fate determination cellular response to stress di-, tri-valent inorganic cation transport embryonic pattern specification neurotransmitter transport

Ras protein signal transduction

regulation of ARF protein signal transduction sexual reproduction

small GTPase mediated signal transduction vesicle-mediated transport

\section{H3K9me3 GO term}

alcohol catabolic process cellular response to hydrogen peroxide cGMP biosynthetic process glucose metabolic process lipid catabolic process phosphorus metabolic process proteolysis

response to oxidative stress Rho protein signal transduction small GTPase mediated signal transduction p-value
0.003692 0.024047 0.025121 0.014926 0.014278 0.026237 0.009567 0.010532 0.012046 0.022085

p-value 0.065297 0.003342 0.00373 0.025972 0.06103 0.00224

0.015337

3.13E-05 0.007252 0.020446 


\section{H3K9me3 methyltransferase SET-25 is required for heterochromatin formation}

Next, we examined the role of MET-2 and SET-25 for higher-order heterochromatin, as visualized by transmission electron microscopy (TEM). Wild-type nuclei from young embryos were predominantly electron translucent whereas nuclei from older embryos contained many electron dense regions (EDRs) (Figure 2A), as observed previously (Mutlu et al., 2018). EDRs represent heterochromatin regions based on morphology and on the enrichment for silencing marks such as H3K9me3 (Rübe et al., 2011). In met-2 mutants, EDRs are paler than normal and delayed in their appearance (Mutlu et al., 2018). In set-25 mutants, we did not detect any EDRs through the 200-cell stage, a phenotype that was stronger than met-2 mutants (Figure 2A). As a control for TEM fixation and imaging, we examined the cytosol of wild-type and set-25 mutants, using a threshold value to define electron dense regions. Both genotypes had darkly stained cytosolic regions (Figure 2B). These data show that disruption of EDR formation tracks with H3K9me3: intermediate EDR formation in met-2 mutants correlates with intermediate H3K9me3 levels and absent EDRs in set-25 mutants with absent H3K9me3. These results demonstrate that neither $\mathrm{H} 3 \mathrm{~K} 9 \mathrm{me} 3$ nor the formation of large-scale, higher-order heterochromatin is required to terminate developmental plasticity. The data suggest that coordination between the termination of plasticity and generation of heterochromatin relies on distinct readouts from MET-2: formation of heterochromatin from $\mathrm{H} 3 \mathrm{~K} 9 \mathrm{me} 3$ and termination of plasticity by $\mathrm{H} 3 \mathrm{~K} 9 \mathrm{me} 1 / \mathrm{me} 2$ (Figure 2C).

Figure 2. H3K9me3 methyltransferase SET-25 is required for heterochromatin formation.

A. TEM of representative nuclei from WT or set-25 mutant embryos. Scale bars $1 \mu \mathrm{m}$. For set-25 embryos: N=2, 14 "Plastic", 10 "Transition" and 5 "Restricted" embryos, with $>20$ nuclei for each group. 
B. Contrast of the cytosol in WT or set-25 mutants and intensity thresholding (red) to define electron-dense structures.

C. Summary of results in WT, met-2 and set-25 mutant embryos. Embryonic stages analyzed in this study are early ( $<20$ cell), mid (21-200 cell) and late ( $>200$ cell).

Figure 2

A

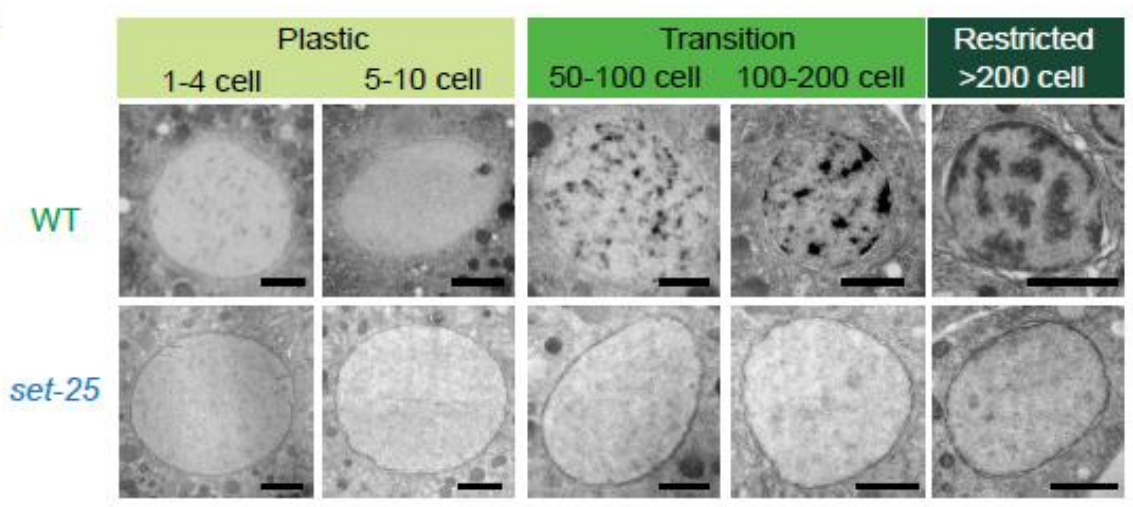

B
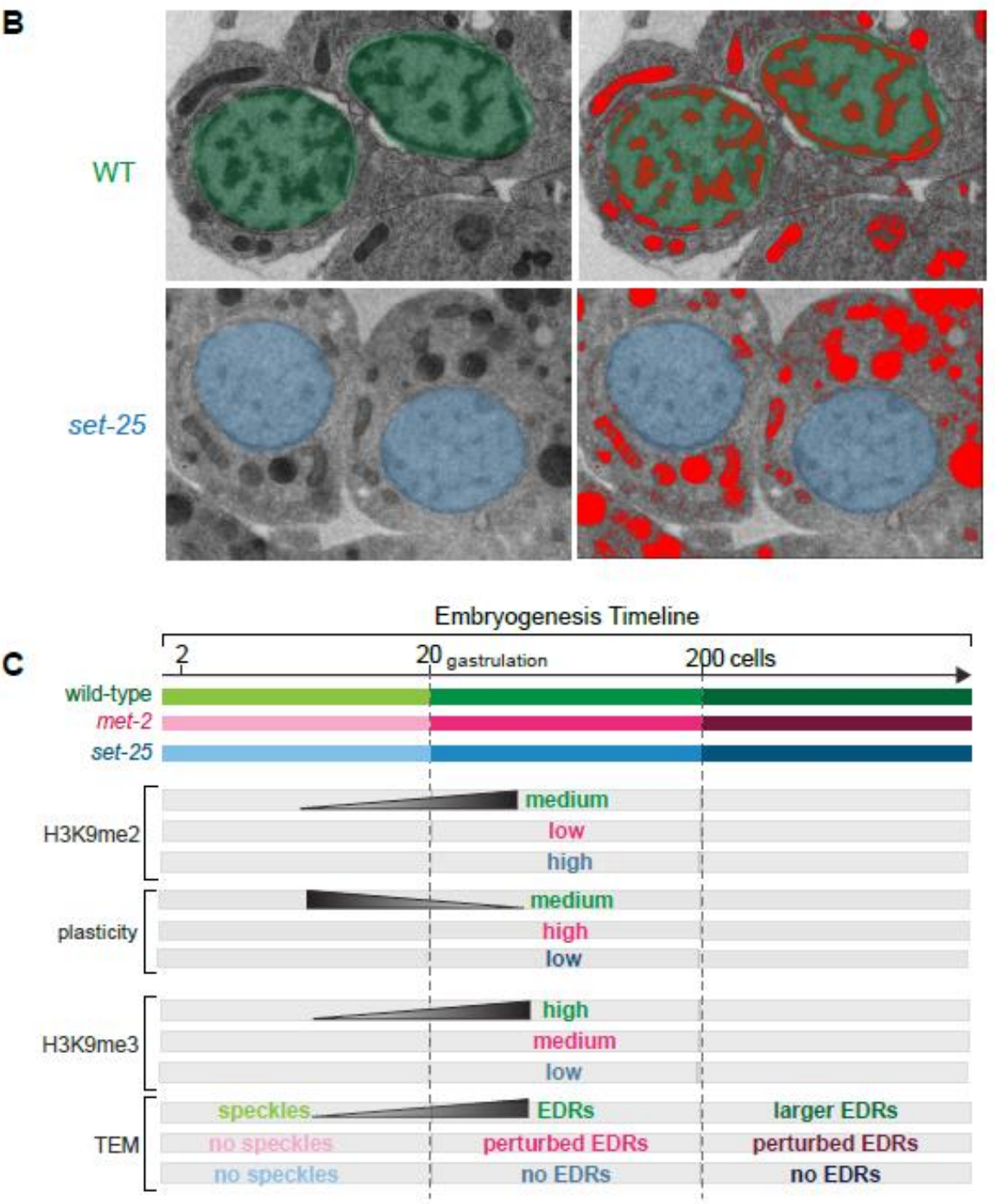


\section{H3K9 de-methylation is not a timer for establishing $\mathrm{H} 3 \mathrm{~K} 9 \mathrm{me} 2$ domains at}

\section{gastrulation.}

The above data suggest that MET-2 helps coordinate two critical events in the early embryo: loss of developmental plasticity by H3K9me1/me2 and generation of higherorder heterochromatin by $\mathrm{H} 3 \mathrm{~K} 9 \mathrm{me} 3$. Both of these processes occur during gastrulation as $\mathrm{H} 3 \mathrm{~K} 9 \mathrm{me}$ accumulates, raising the question of what mechanisms regulate $\mathrm{H} 3 \mathrm{~K} 9 \mathrm{me}$ temporally (Figure 3A). Since MET-2 acts upstream of SET-25 (Towbin et al., 2012) and H3K9me2 increased most dramatically from fertilization to gastrulation (Mutlu et al., 2018), we focused on the timing of H3K9me2 onset.

Initially, we wondered if an $\mathrm{H} 3 \mathrm{~K} 9$ me2 demethylase might act in early embryos to remove $\mathrm{H} 3 \mathrm{~K} 9 \mathrm{me} 2$. To test this idea, we examined a mutant for the H3K9me2 demethylase jmjd-1.2 (Kleine-Kohlbrecher et al., 2010). In jmjd-1.2(tm3713) mutants that don't produce JMJD-1.2 (Myers et al., 2018), H3K9me2 was extremely low in early embryos, like wild-type, and was established normally at gastrulation (Figure 3B-D). These data suggested that histone de-methylation is not part the H3K9me2 timer and led us to focus on MET-2.

Figure 3. H3K9me1/me2 methyltransferase MET-2 is regulated during embryogenesis to form heterochromatin.

A. Diagram showing a timeline for $C$. elegans embryogenesis and a summary of changes that accompany differentiation. With each cell division and passing time, the total number of cells, amount of DNA per embryo and the nuclear-to-cytoplasmic ratio per cell increases. The transition from light to dark green represents initiation of gastrulation around the 28-cell stage. Zygotic transcription is initiated at the 4-cell stage, but a big wave coincides with gastrulation (Levin et al., 2012; Schauer and Wood, 1990; StorferGlazer and Wood, 1994). All of these changes are candidates for dictating the timing of H3K9me2.

C. H3K9me2 levels in wild-type vs. H3K9me2 demethylase jmjd-1.2 mutants at pregastrula (4-cell and 8-cell stage) and gastrula (21-50 cell) stages. 
D-E. Single nuclei in interphase showing H3K9me2 levels in wild-type vs. jmjd-1.2 mutants. Quantitation of H3K9me2 levels per nucleus. Early jmjd-1.2 embryos do not have increased $\mathrm{H} 3 \mathrm{~K} 9 \mathrm{me} 2$.

Figure 3

A

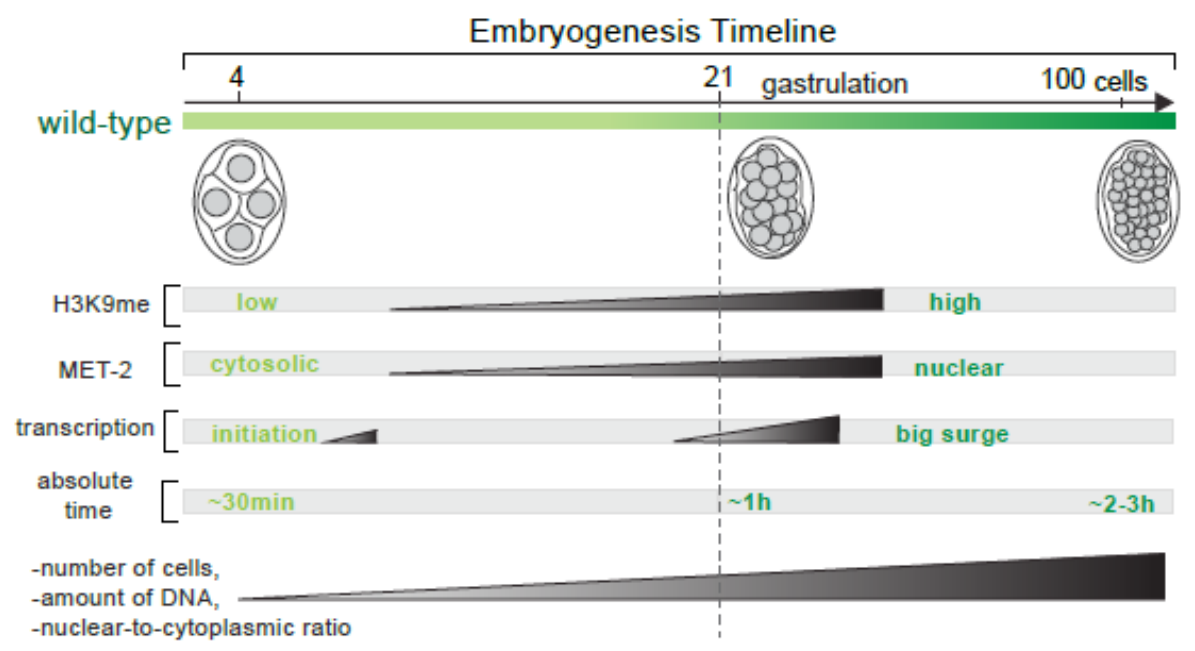

B

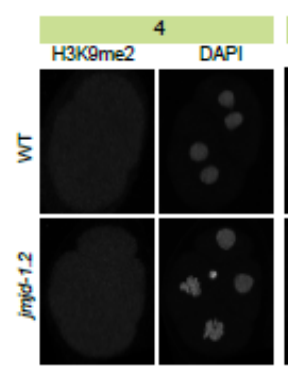

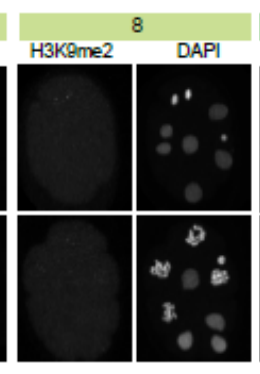

C

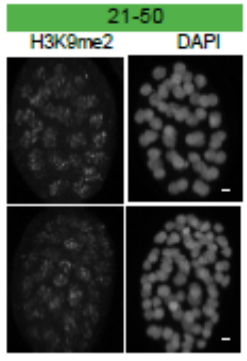

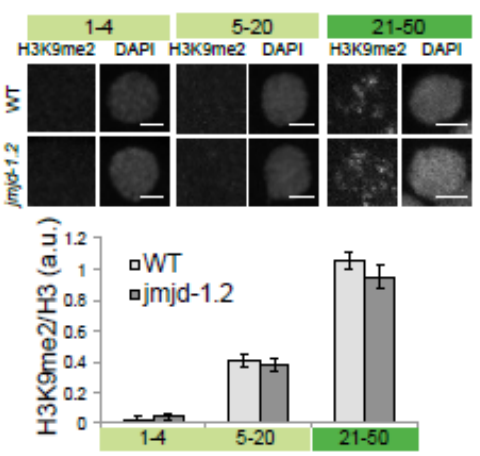

\section{Zygotic transcription is not rate-limiting for $\mathrm{H} 3 \mathrm{~K} 9$ di-methylation.}

The onset of gastrulation and surge in $\mathrm{H} 3 \mathrm{~K} 9 \mathrm{me} 2$ is accompanied by a big wave in zygotic transcription (Baugh, 2003; Edgar et al., 1994; Hsu et al., 2015; Levin et al., 2012; StorferGlazer and Wood, 1994; Yuzyuk et al., 2009). We hypothesized that met-2 or its cofactors could be activated in the embryo as zygotic transcription begins (Figure 4A, Model 1). In addition, transcription elongation could be rate-limiting for recruiting MET-2 to specific loci through interactions with the RNAi machinery ((Guang et al., 2010), Figure 4A, Model 2). 
We tested these models in two ways. First, we blocked zygotic transcription and examined whether the onset of H3K9me2 was disturbed. Second, we tested whether a zygotic copy of met-2 could rescue H3K9me2 in the absence of maternal MET-2. For these experiments, we were able to compare H3K9me2 levels across different genotypes by including wild-type embryos marked with a fluorescent tag as an on-slide control. Control embryos and test embryos were processed together on the same slide and imaged with identical settings (Figure 4B).

To block transcription, we inactivated the canonical TFIID subunit, taf-6.2, with a temperature-sensitive mutation (ax514) (Bowman et al., 2011), and a core subunit of RNA Polymerase II, ama-1, by RNAi. To assess the strength of the block on transcription, we stained embryos with the H5 Polymerase II antibody against the phosphorylated Ser2 on the CTD domain, which is a hallmark of transcriptional elongation (Bregman et al., 1995; Seydoux and Dunn, 1997). Under our conditions, H5 Polymerase II signal was undetectable after blocking zygotic transcription, whereas non-specific staining of $\mathrm{P}$ granules by the H5 antibody served as a positive control. (Figure 4C, D). Despite the lack of detectable H5, H3K9me2 levels were identical to wild-type embryos (Figure 4C, E), suggesting that neither zygotic genes nor elongating Polymerase II were rate-limiting for H3K9me2 onset.

The transcriptional block suggested that MET-2 and its regulators must be contributed maternally and independent of zygotic transcription. To test this idea further, we examined RNA expression of met-2 and its binding partners lin-65 and arle-14 (Mutlu et al., 2018), which are required for H3K9me2. met-2, lin-65 and arle-14 transcripts were abundant in early embryos, before the initiation of zygotic transcription (Levin et al., 2012; 
Seydoux and Fire, 1994; Tintori et al., 2016), revealing that these RNAs were deposited by the mother. To test if zygotic MET-2 could rescue H3K9me2 in embryos, we mated met-2 mutant mothers with wild-type males and analyzed the progeny, which carried a single zygotic copy of the wild-type met-2 locus. Zygotic met-2 could not restore H3K9me2 to mutant embryos (Figure 4F). Similarly, neither zygotic lin-65 nor zygotic arle-14 could rescue $\mathrm{H} 3 \mathrm{~K} 9 \mathrm{me} 2$ from maternally mutant mothers (Figure 3.2G). Moreover, when we mated wild-type mothers with met-2::gfp males, the resulting met-2::gfp progeny never expressed GFP (Figure $\mathbf{4 H}, \mathbf{I})$. These results demonstrate that maternally deposited MET-2 and its binding partners are responsible for establishing H3K9me2 in embryos, and that the onset of transcription cannot account for the timing of $\mathrm{H} 3 \mathrm{~K} 9 \mathrm{me} 2$ deposition.

Figure 4. Zygotic transcription is not rate-limiting for H3K9 di-methylation.

A. Two models describe how initiation of zygotic transcription might be important for dictating the timing of $\mathrm{H} 3 \mathrm{~K} 9 \mathrm{me}$. Model 1: Transcription could be important for the production of MET-2 protein or an activator of MET-2. Model 2: Transcription itself might be rate-limiting to recruit MET-2 to chromatin (Bühler and Moazed, 2007; Guang et al., 2010)

B. Experimental design. Wild-type embryos (green) containing a single copy ZEN-4::GFP or HIS-72::mCHERRY marker were analyzed on the same slide as unlabeled mutant embryos (yellow). This approach controlled for staining variability, thereby enabling an accurate comparison between different genotypes.

C. Gastrula embryos stained with an antibody that detects the elongating form of RNA Polymerase II (H5; green) or H3K9me2 (red). Scale bar $2 \mu \mathrm{m}$. Transcription was blocked by combining ama-1 RNAi with the ax514 mutation in the initiation factor taf-6.2. White arrow points to non-specific P-granule (Wang and Seydoux, 2014) staining by the H5 antibody and serves as a staining control.

D-E. Quantitation of mean signal intensity per nucleus for Pol II and H3K9me2 in wildtype vs. transcriptionally impaired embryos on the same slide. Note that transcription elongation is undetectable but $\mathrm{H} 3 \mathrm{~K} 9 \mathrm{me} 2$ levels are unaffected.

F-G. H3K9me2 levels in gastrula embryos that lack maternal met-2, lin-65 or arle-14 but contain a paternal copy. The genotype of the mother is highlighted in red, the father's in blue. Zygotic copies of these genes cannot rescue H3K9me2 in the embryo.

H-I. MET-2::GFP levels in gastrula embryos that lack a maternal copy of the construct, but inherit a paternal copy. Note that the paternal copy of MET-2 is not expressed in the embryo and maternal MET-2 sufficient for all H3K9me2 during embryogenesis. 
Figure 4
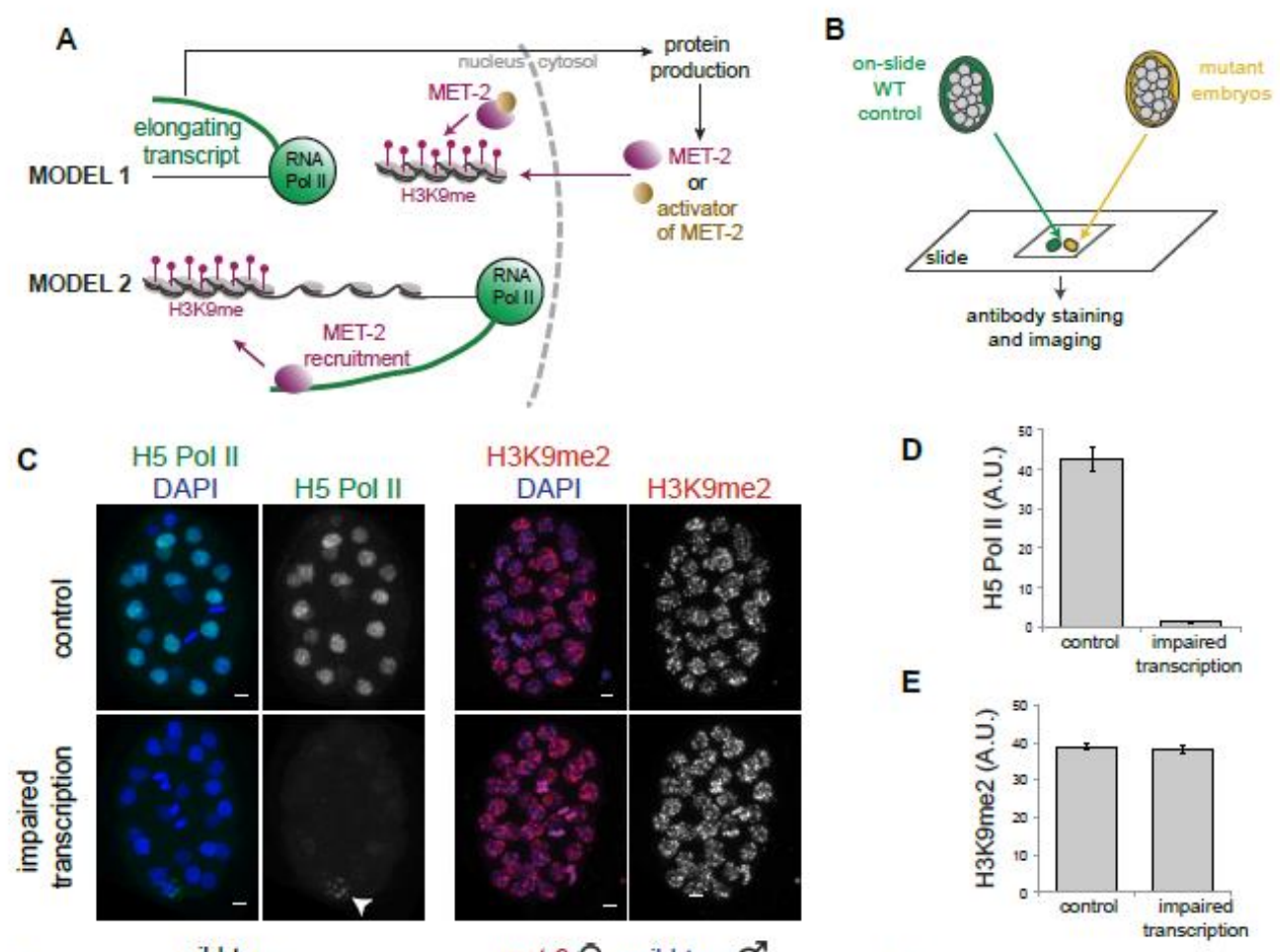

H3K9me2

C

DAPI
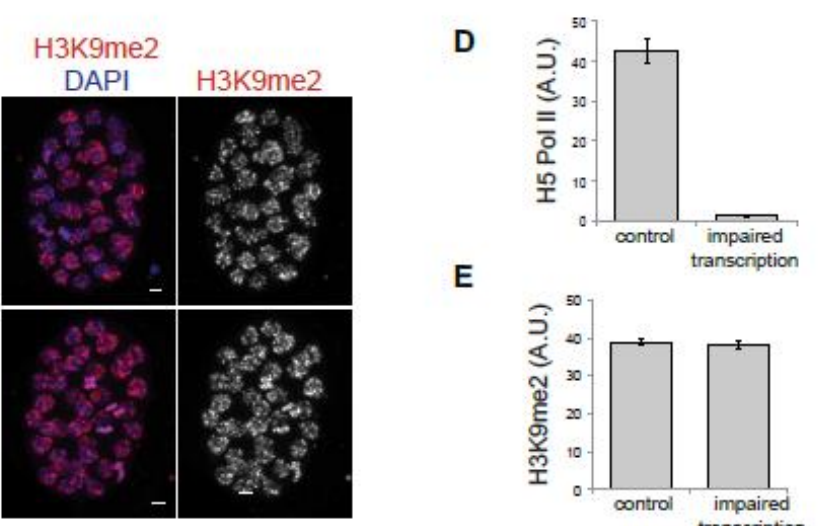

$\mathbf{F}$
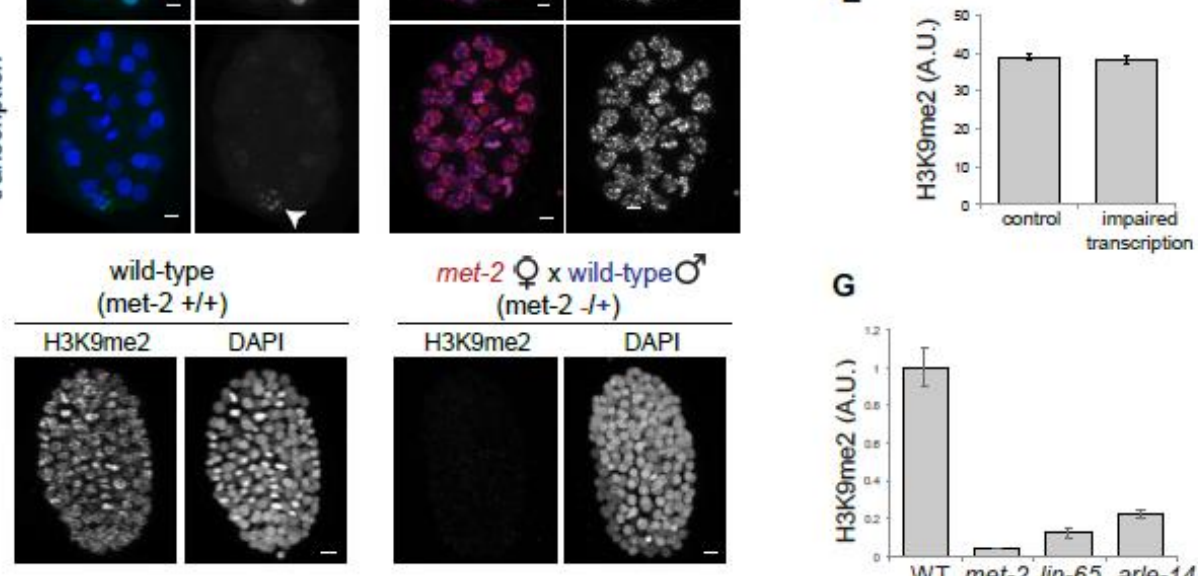

G

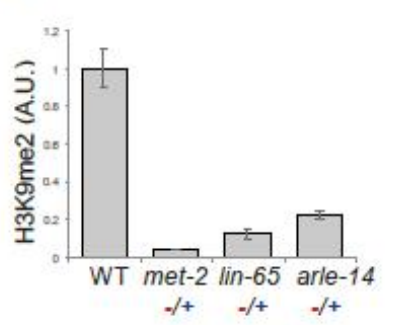

H

met-2::gfp $+1+$
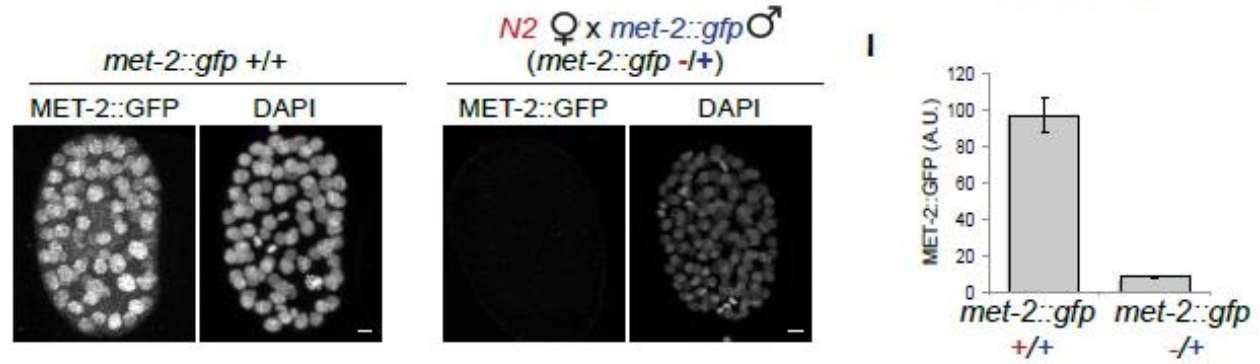
Length of interphase, but not cell counting mechanisms, dictates timing of H3K9me2.

The transcription block ruled out some expected mechanisms for H3K9me2 onset. To gain a broader perspective on regulation of $\mathrm{H} 3 \mathrm{~K} 9$ me onset, we considered alternative models. Embryonic timing has been studied extensively for the onset of zygotic genome activation (ZGA), and processes that dictate ZGA could also apply to H3K9me. One model postulates that cell counting mechanisms such as the amount of DNA in the embryo could be a timer (Dekens et al., 2003; Newport and Kirschner, 1982a). A second model focuses on the changes in the nuclear-to-cytoplasmic ratio as embryonic cells divide, which could be critical for diluting or concentrating a maternal repressor/activator (Newport and Kirschner, 1982b; Pritchard and Schubiger, 1996). A third model predicts that fertilization initiates a process that builds gradually as a direct readout of time passed (Ferree et al., 2016; Howe and Newport, 1996; Kimelman et al., 1987; Treen et al., 2018; Yuan et al., 2016). We tested whether any of these models could explain timing of H3K9me2 onset.

To determine if cell counting is important, we uncoupled the number of cells produced over a given unit of time. We inactivated div-1, a subunit of DNA polymerasealpha primase complex, by using a temperature-sensitive mutation (or148) to extend the duration of S-phase and slow down cell divisions (Encalada et al., 2000). One hour after the 2-cell stage, wild-type embryos had 25-30 cells, whereas div-1 mutant embryos had 5-15 cells (Figure 5A). div-1 embryos exhibited precocious H3K9me2 based on cell number, but wild-type levels based on time post-fertilization (Figure 5B, C). The amount of H3K9me2 per nucleus was similar in 25-30 cell wild-type embryos and 5-15 cell div-1 
embryos. These delayed div-1 cells had a similar volume to wild-type embryos with the equivalent number of cells (Figure 5D) and comparable amounts of DNA as wild-type embryos that contain the same number of cells (Figure 5E). This result rules out some counting models, specifically the nuclear-to-cytoplasmic ratio, the number of cells or the amount of DNA. In short, it is possible to acquire high levels of H3K9me2 without reaching a certain cell number, nuclear-to-cytoplasmic ratio or undergoing a certain number of cell divisions. Instead, this result suggests that the timing of $\mathrm{H} 3 \mathrm{~K} 9 \mathrm{me} 2$ is dictated by an absolute clock that measures the time spent in interphase ( 1 hour after the 2 -cell stage).

One concern was that the replicative stress or DNA damage in early div-1 embryos caused higher levels of H3K9 methylation to engage DNA repair pathways (Ayrapetov et al., 2014). We hypothesized that if DNA damage in div-1 mutants caused the increase in H3K9me2, one might expect restoring the faster cell cycle in div-1 mutants to lead to even more DNA damage and H3K9me2 (Figure 5F). Alternatively, if the amount of time from fertilization was the critical parameter, then restoring the faster cell cycle to div- 1 mutants would rescue normal timing of $\mathrm{H} 3 \mathrm{~K} 9 \mathrm{me} 2$ accumulation. To restore faster cell cycle progression to div-1 mutant embryos, we inactivated the ATR related gene atl-1 which leads to faster cell cycles but potentially more DNA damage (Brauchle et al., 2003). atl1(RNAi); div-1 double mutants partially suppressed the increase in H3K9me2 (Figure 5GI), suggesting precocious H3K9me2 in div-1 mutants was not due to DNA damage. Instead, timing of H3K9me2 depends on the amount of time from fertilization. 
Figure 5. Slowing down S-phase leads to precocious accumulation of H3K9me2, based on amount of time spent after fertilization.

A. Time-line of embryogenesis with respect to absolute amount of time and number of cells per embryo in wild-type (green) or div-1(or148) mutant (gray) embryos.

B-C. H3K9me2 staining in embryos that contain the same number of cells (8-cell, left panels) or that have developed for the same amount of time after the 2-cell stage (1 hour, right panels). Scale bar $2 \mu \mathrm{m}$. Amount of H3K9me2 tracks with absolue time, not number of cells.

D. Nuclear volume in wild-type vs. div-1(or148) embryos at the 8-cell stage.

E. Mean DAPI intensity in wild-type vs. div-1(or148) embryos at the 8-cell stage.

F. Rationale. Increased H3K9me2 in div-1 mutants could be due to I) the extension of Sphase (light orange) or II) DNA damage (dark orange). Accordingly, restoring the cell cycle by inactivating atl-1 in div-1 mutants is predicted to have two alternative outcomes: I) rescue of cell cycle timing and reduction in $\mathrm{H} 3 \mathrm{~K} 9 \mathrm{me} 2$ (light orange) or II) additional DNA damage and increased $\mathrm{H} 3 \mathrm{~K} 9 \mathrm{me} 2$ (dark orange).

G. H3K9me2 staining in wild-type vs. atl-1 RNAi, div-1(or148) and atl-1 RNAi; div1(or148) double inactivation embryos at the pre-gastrula stage. Color code: wild-type green, atl-1 - purple, div-1 - gray, atl-1;div-1 - blue. In each experiment, wild-type embryos containing zen-4::gfp were included as on-slide controls (not shown).

$\mathrm{H}-\mathrm{I}$. Single nuclei in interphase showing $\mathrm{H} 3 \mathrm{~K} 9 \mathrm{me} 2$ levels and quantitation. Note that at1 RNAi partially rescues H3K9me2 levels in div-1 mutants in support of Scenario I (light orange from $A$ ). 
Figure 5

A

B
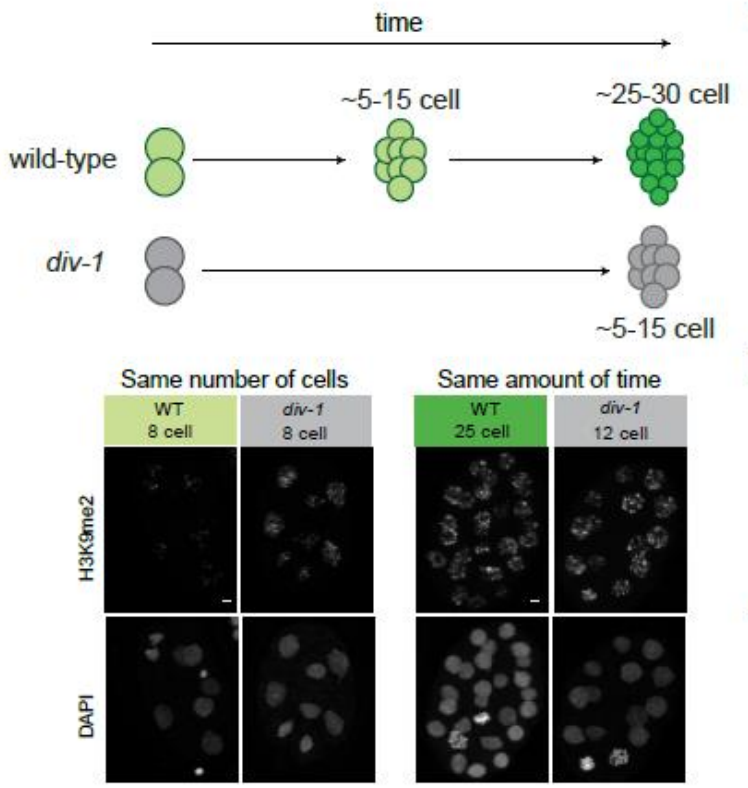

C

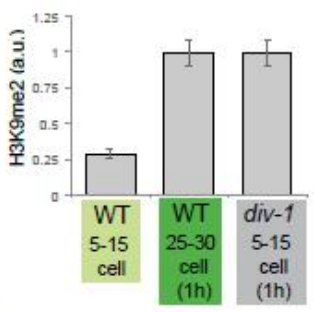

D

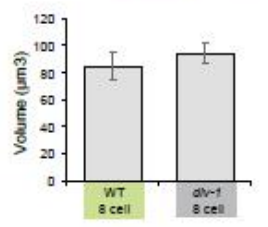

E

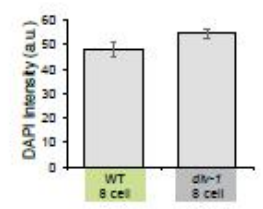

$\mathbf{F}$

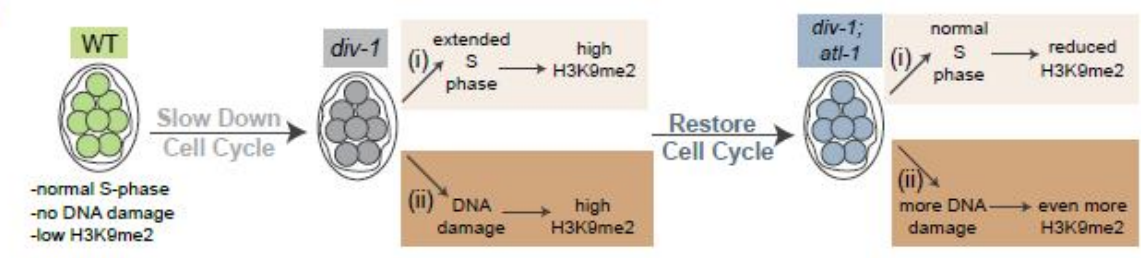

G
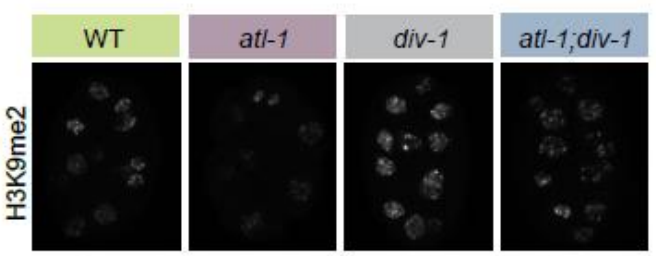

H
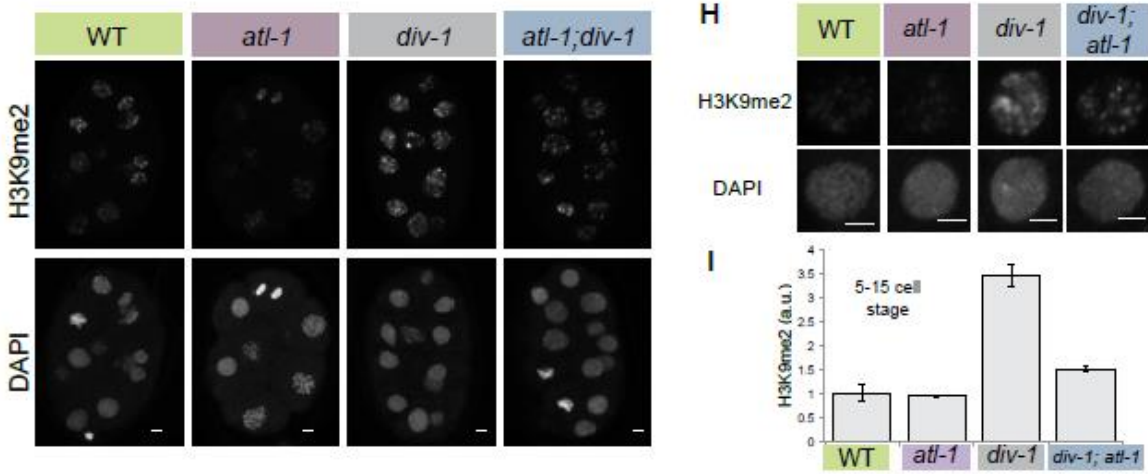

Our previous work revealed that MET-2 is initially partitioned between the nucleus and cytoplasm, but becomes concentrated within nuclei as embryos mature (Figure 6A, (Mutlu et al., 2018)). Nuclear MET-2 is rate-limiting for H3K9me2 levels and gradually 
accumulates in nuclei with its binding partners LIN-65 and ARLE-14 (Mutlu et al., 2018).

We wondered if precocious $\mathrm{H} 3 \mathrm{~K} 9 \mathrm{me} 2$ in div-1 mutants might reflect precocious accumulation of the MET-2 complex in nuclei. Indeed, MET-2 and its binding partners each accumulated in the nucleus earlier compared to wild-type embryos (Figure 6B-G). We hypothesize that the cumulative time spent in interphase after fertilization permits relocalization and activation of MET-2, and thereby dictates the onset of H3K9me2.

Figure 6. Slowing down S-phase leads to precocious accumulation of MET-2 and binding partners in the nucleus.

A. MET-2::GFP localization and H3K9me2 levels during embryogenesis. MET-2::GFP (green), H3K9me2 (red), DAPI (blue), Scale bar $2 \mu \mathrm{m}$. Note that MET-2::GFP accumulates in the nucleus as $\mathrm{H} 3 \mathrm{~K} 9 \mathrm{me} 2$ domains are formed.

B,C. Wild-type vs div-1 (or148) embryos at the pre-gastrula stage stained with an antibody against endogenous MET-2 on the same slide. Quantitation of protein levels per nucleus. D,E. Progeny of lin-65::3xflag worms fed with empty vector vs div-1 RNAi. Embryos at the pre-gastrula stage were stained with a FLAG antibody. Quantitation of protein levels per nucleus.

F,G. Wild-type vs div-1 (or148) embryos at the pre-gastrula stage stained with an antibody against endogenous ARLE-14 on the same slide. Quantitation of protein levels per nucleus. 
Figure 6

A

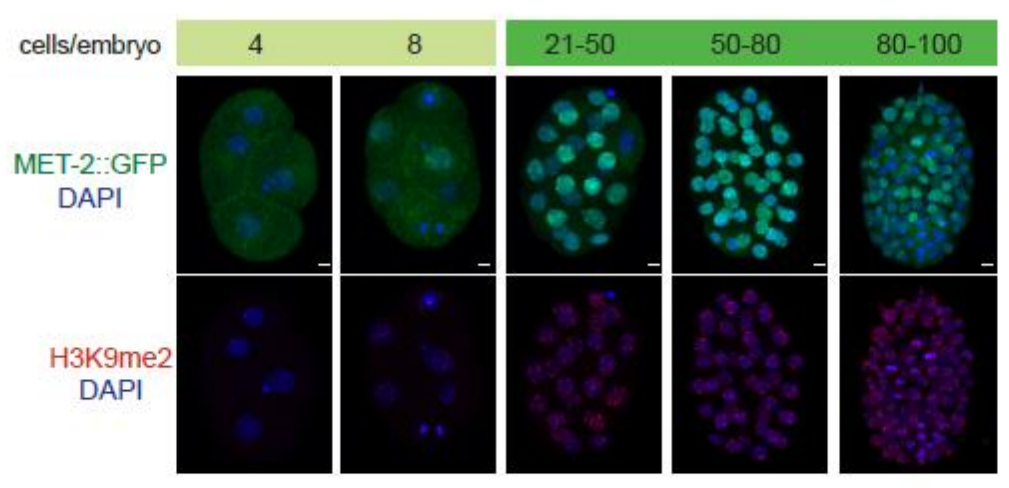

B

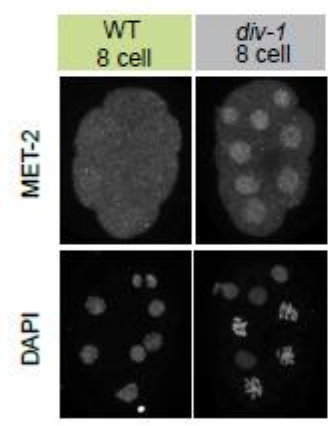

C

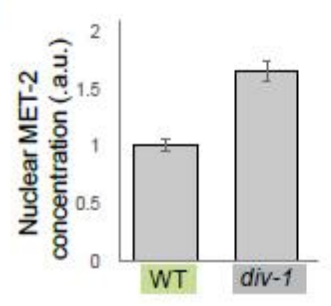

D

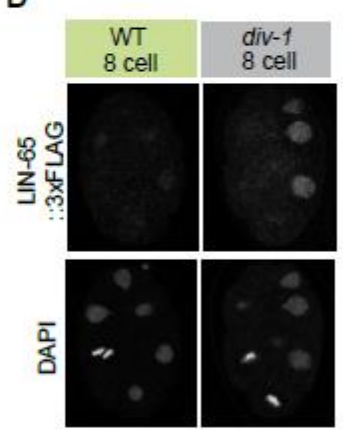

E

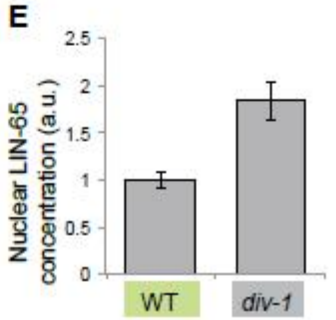

$\mathbf{F}$

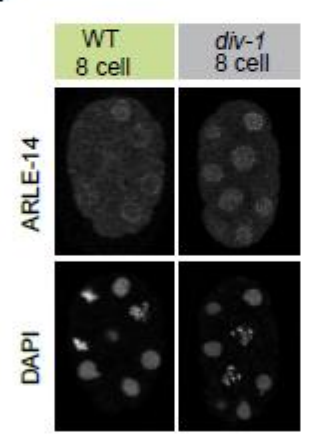

G

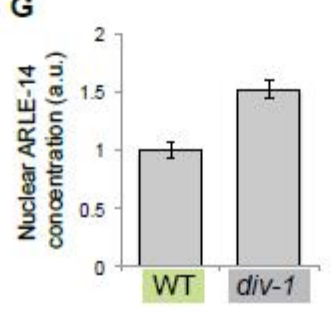

\section{DISCUSSION}

This study has made three contributions to understand the timing and function of H3K9me during embryogenesis. First, the methyltransferase MET-2 promotes loss of developmental plasticity through $\mathrm{H} 3 \mathrm{~K} 9 \mathrm{me} 1 / \mathrm{me} 2$, and formation of higher-order heterochromatin through $\mathrm{H} 3 \mathrm{~K} 9 \mathrm{me}$. Second, several models cannot account for the onset of MET-2 activation, including cell counting, the nuclear-to-cytoplasmic ratio or 
zygotic transcription. Third, the cumulative amount of time early embryonic cells spend in interphase, specifically S phase, influences accumulation of MET-2 in the nucleus and determines the onset of H3K9 di-methylation.

\section{Distinct roles for di vs. tri methylated $\mathrm{H} 3 \mathrm{~K} 9$ in cell fate potential and formation of higher-order heterochromatin}

By sequence, MET-2 is most similar to vertebrate SETDB1(Poulin et al. 2005; Andersen and Horvitz 2007). Both enzymes can catalyze mono and di-methylation on H3K9, and directly or indirectly regulate H3K9me3 (Basavapathruni et al., 2016; Loyola et al., 2009; Towbin et al., 2012; Wang et al., 2003). SET domain methyltransferases contain a 'switch position' in their catalytic site that determines the degree of methylation, with bulkier residues able to accommodate mono- and di- but not tri-methylation (Jih et al., 2017). MET-2 and SETDB1 have a bulky Tryptophan residue in the switch position, which suggests that these enzymes favor mono- and di-methylation in the absence of regulatory partners. However, the presence of partially redundant H3K9 methyltransferases in mammals (including SUV39h1/2, G9a and PRDM2/3/16) and in some cases lethal phenotypes associated with loss of individual enzymes have made it hard to dissect the roles for di- vs. tri-methylation. In worms, the differential effects of the two H3K9 methyltransferases met-2 and set-25 on mono, di and tri methylated H3K9 provide a means to distinguish the roles of these histone marks.

Developmental potential was inversely correlated with H3K9me2 (Figure 1, Figure 2C): met-2, wild-type and set-25 embryos had low, average and high levels of 
H3K9me2, respectively. met-2 mutants were able to alter their developmental fate robustly, wild-type embryos less so, and set-25 mutants least of all. Double mutants between met-2 and set-25 lacked $\mathrm{H} 3 \mathrm{~K} 9 \mathrm{me} 2$, and as predicted, they extended plasticity like met-2 single mutants. At later stages, met-2 mutants were resistant to the CFC assay, suggesting that $\mathrm{H} 3 \mathrm{~K} 9 \mathrm{me} 2$ is important for the timely loss of plasticity but not absolutely required. Additional regulators such as Polycomb and Notch may account for the partial requirement (Djabrayan et al., 2012; Joshi et al., 2010; Yuzyuk et al., 2009) We note that our results do not rule out a role for $\mathrm{H} 3 \mathrm{~K} 9 \mathrm{me} 1$, but that $\mathrm{H} 3 \mathrm{~K} 9 \mathrm{me} 1$ levels did not correlate with plasticity as closely as $\mathrm{H} 3 \mathrm{~K} 9 \mathrm{me} 2$ levels.

EDRs were reduced in met-2 mutants and absent in set-25 embryos. Similarly, H3K9me3 was reduced in met-2 and absent in set-25 mutants, making H3K9me3 an excellent candidate to mediate higher-order heterochromatin. An intriguing but speculative idea is that emergence of EDRs depends on $\mathrm{H} 3 \mathrm{~K} 9 \mathrm{me} 3$ quantitatively rather than responding to an all-or-nothing threshold (Larson et al., 2017; Strom et al., 2017).

\section{Higher-order heterochromatin and loss of developmental plasticity}

An absence of heterochromatin could provide a permissive environment to transcribe diverse genes, an important feature of pluripotent embryos. However, we note that neither loss of EDRs in set-25 mutants, nor absence of all H3K9me in met-2; set-25 double mutants, did not enable HLH-1 to activate muscle genes ubiquitously. Therefore, additional mechanisms must exist to curtail the ability of cells to respond to a heterologous regulator. For example, H3K27me3 is present in met-2; set-25 mutants (Towbin et al., 
2012) and could compensate for the loss of H3K9 methylation. Alternatively, the local deposition of nucleosomes over transcription factor binding sites or within transcribed regions could block plasticity (Gaspar-Maia et al., 2011). In vertebrates, H3K9me3-rich domains can interfere with transcription factor binding to block reprogramming of induced pluripotent stem cells (Soufi et al., 2012). This result suggests that 'reverse development', as seen in reprogramming, may be qualitatively different from 'forward development', when plasticity is lost during embryogenesis. For example, H3K9me3 may initiate processes that eventually solidify a cell fate and block reprogramming in differentiated cells, but these processes may not yet be complete in gastrula-stage embryos.

\section{Zygotic transcription is not rate-limiting for $\mathrm{H} 3 \mathrm{~K} 9 \mathrm{me}$.}

RNAi pathways are critical to target heterochromatin machinery in worms and other organisms such as S. pombe (Moazed, 2009). In particular, the piwi pathway and the nuclear RNAi (nrde) pathway both target repeat sequences that make up the bulk of heterochromatin and are marked by H3K9me2 in C. elegans (Ashe et al., 2012; McMurchy et al., 2017; Ni et al., 2014; Weick and Miska, 2014). While it is known that the RNAi machinery targets $\mathrm{H} 3 \mathrm{~K} 9$ methylation, it was not clear whether these components dictate the timing of $\mathrm{H} 3 \mathrm{~K} 9 \mathrm{me} 2$ in embryos.

The nrde pathway acts co-transcriptionally and inhibits Polymerase II during the elongation phase of transcription through the deposition of H3K9me (Guang et al., 2010). Concomitant with a big wave in zygotic transcription, embryonic nuclei acquire methylated H3K9me (Figure $\mathbf{3 A}$ ), suggesting transcription elongation could be rate-limiting for 
H3K9me2 deposition during embryogenesis. However, H3K9me2 levels were not affected after blocking transcription elongation (Figure 4), suggesting that it is not the rate-limiting component. We note that while transcription elongation was undetectable under our experimental conditions, abortive transcription may still occur. Thus, our results do not rule out Pol II transcription or RNAi as a mechanism for targeting H3K9 methylation but rule them out as timers. An intriguing model is that the absence of H3K9 methylation in early embryos provides a window of opportunity where repetitive sequences can be transcribed and be targeted by the RNAi machinery to acquire H3K9me (McMurchy et al., 2017; Penke et al., 2016; Yu et al., 2013; Zeller et al., 2016).

\section{Zygotic transcription and chromatin organization.}

The nature of the relationship between zygotic transcription and chromatin regulation has been uncertain. Chromatin regulation could precede and initiate zygotic transcription (Meier et al., 2018; Østrup et al., 2013). Conversely, zygotic transcription may help shape chromatin structure, a model that has been tested by several studies: A study that analyzed the spatial genome organization in fly embryos revealed that early expressed genes correlate with the boundaries of Topologically Associating Domains (TADs). However, emergence of these structures are not dependent on transcription (Hug et al., 2017). Another study in Xenopus embryos mapped the distribution of histone modifications across the genome, and found that $\mathrm{H} 3 \mathrm{~K} 4 \mathrm{me} 3$ and $\mathrm{H} 3 \mathrm{~K} 27 \mathrm{me} 3$ domains were established independently of zygotic transcription (Hontelez et al., 2015). Similarly, our results suggest Pol II transcription is not rate-limiting for the establishment of $\mathrm{H} 3 \mathrm{~K} 9 \mathrm{me}$ in early embryos. 


\section{Classical models of time-keeping and H3K9 methylation}

Classical models of embryonic time-keeping include i) an "absolute clock" that depends on the time from fertilization (Howe and Newport, 1996; Treen et al., 2018), ii) the increasing nuclear-to-cytoplasmic ratio (Newport and Kirschner, 1982b; Pritchard and Schubiger, 1996) or iii) cell counting via increasing DNA content in the embryo, which titrates a maternal repressor (Dekens et al., 2003; Newport and Kirschner, 1982a). These models have mostly been studied in the context of zygotic genome activation. One study analyzed local changes in chromatin organization during fly embryogenesis and found that promoter accessibility is controlled by the nuclear-to-cytoplasmic ratio (Blythe and Wieschaus, 2016). However, large-scale changes in chromatin organization during development such as heterochromatin formation had not been studied through the lens of these models.

In this study, we applied these models to H3K9 methylation, which emerges during gastrulation (Mutlu et al., 2018). Our analysis of div-1 mutants ruled out cell counting as a potential timer and suggests that $\mathrm{H} 3 \mathrm{~K} 9 \mathrm{me} 2$ depends on an absolute clock for nuclear entry of MET-2 and its binding partners. div-1 mutants specifically extend S-phase compared to wild-type embryos (Encalada et al., 2000), suggesting that the cumulative time that early embryonic cells spend in S-phase is critical for measuring time.

\section{Spatial regulation of MET-2 and timing of $\mathrm{H} 3 \mathrm{~K} 9$ methylation}

MET-2 moves gradually into nuclei in the pre-gastrula embryo, but is released into the cytosol during mitosis (Mutlu et al., 2018). Early embryonic cells divide rapidly, with a 40- 
minute cell cycle that likely interferes with the accumulation of MET-2 in nuclei. Slowing down the cell cycle in div-1 embryos leads to precocious accumulation of MET-2 in the nucleus (Figure 6). Consistent with this idea, cells that divide slowly compared to other cell lineages (e.g. the E cells (Sulston et al., 1983)) accumulate more nuclear MET-2 and more H3K9me2 than rapidly dividing cells (data not shown). In sum, our data suggest that the cumulative time early embryonic cells spend in interphase could be important for i) MET-2 accumulation in the nucleus and ii) deposition of H3K9me by nuclear MET-2.

Spatial regulation of proteins provides a rapid means to restrict their activity and is a common theme in temporal regulation of developmental processes. For instance, Prmt1 and SIRT1 each transition from the cytosol to the nucleus, or vice versa, to alter their activity upon differentiation (Ancelin et al., 2006; Hisahara et al., 2008). Similarly, the onset of zygotic transcription is dictated by the OMA proteins, which sequester a critical cofactor for TFIID in the cytoplasm (Guven-Ozkan et al., 2008). Our study provides a third example, where the embryonic clock for H3K9me depends on the spatial regulation of MET-2 and its binding partners.

\section{MATERIALS AND METHODS}

Strains. Strains were maintained at $20^{\circ} \mathrm{C}$ according to (Brenner, 1974), unless stated otherwise*.

N2 (wild-type Bristol)

${ }^{\star}$ EU548 div-1(or148ts) III. (Encalada et al., 2000)

*KW1975 taf-6.2(ax514); unc-17(e113) IV.

SM2440 jmjd-1.2 (tm3713) IV. (Kleine-Kohlbrecher et al., 2010)

EL597 omls 1 [Cb-unc-119 (+) met-2::gfp II].

SM2575 lin-65::3xflag I.

SM2333 pxSi01 (zen-4::gfp, unc-119+) II; unc-119(ed3) III.

KM167 HS::hlh-1, (Fukushige and Krause, 2005). 
SM1623 HS::hlh-1; met-2 (ok2307) III.

JAC500 his-72(csb43[his-72::mCherry]) III. (Norris et al., 2015)

Antibody staining: Antibody staining was performed as described previously (Mutlu et al., 2018). The following antibodies were used for immunostaining by $5 \mathrm{~min} 2 \%$ paraformaldehyde (PFA), 3 min methanol (for all except PHA-4, which was fixed with 10min 2\% PFA, 3min methanol). H5 Pol II staining followed a completely different protocol described in (Kaltenbach et al., 2000).

H3K9me2 (1:200) Abcam ab1220, MABI0307 Kimura 6D11

Histone H3 (1:500) Abcam ab1791

Pan-histone (1:500) Chemicon/Millipore MAB052

FLAG M2 (1:100) Sigma F1804

MET-2 (1:500) Raised against the first 17 amino acids of MET-2 and affinity purified, a gift from Eleanor Maine.

ARLE-14 (1:500) Generated by our lab as described in (Mutlu \& Mango, submitted). H5 Polymerase II (1:100) Covance MMS129-R

Paramyosin (1:50) Developmental Studies Hybridoma Bank 5-23

PHA-4 N-terminus (1:1000) (Kaltenbach et al., 2005)

TEM was done as described previously (Mutlu et al., 2018).

Quantitation of histone modifications and nuclear proteins. Analysis was done as described in (Mutlu et al., 2018). Briefly, embryos were imaged with a ZEISS LSM700 or LSM880 Confocal Microscope and analyzed by Volocity Software. Signal intensity of marks were calculated for each nucleus and average values for nuclei at designated embryonic stages plotted.

Transcription blocking. KW1975 taf-6.2(ax514) was maintained at $15^{\circ} \mathrm{C}$. For experiments, KW1975 L4s were fed bacteria containing an ama-1 RNAivector. In parallel, SM2233 L4s were fed with bacteria containing empty vector. Both strains were grown at $15^{\circ} \mathrm{C}$ for $50-60$ hours. Adult worms were dissected at $26^{\circ} \mathrm{C}$ and $1-4$ cell embryos were transferred onto the same poly-L-lysine slide. Embryos were aged for 1 hour at $26^{\circ} \mathrm{C}$ in a 
humidity chamber and stained for H3K9me2. For H5 Polymerase II stains, wild-type JAC500 worms fed with empty vector were used as an on-slide control instead of SM2233.

Pouring RNAi plates. RNAi clones from the Ahringer library were used unless stated otherwise. First, identity of clones was confirmed by sequencing. To pour plates, bacteria were grown in $5 \mathrm{ml} \mathrm{LB}$ with $5 \mu \mathrm{l}$ Carbenicillin $(100 \mathrm{mg} / \mathrm{ml})$ for $6-8$ hours at $37^{\circ} \mathrm{C}$ and pelleted at 4000 rpm for 10 minutes. The bacterial pellet was resuspended in $400 \mu$ l $0.5 \mathrm{M} \mathrm{IPTG,}$ $30 \mu 1$ 100mg/ml Carb and $70 \mu \mathrm{l}$ Nuclease-free water. $5 \mathrm{ml}$ NGS plates were seeded with $100 \mu \mathrm{l}$ of resuspended bacterial solution and kept at room temperature for 2 days before use.

div-1 experiments. div-1(or148ts) was maintained at $15^{\circ} \mathrm{C}$ and shifted to $26^{\circ} \mathrm{C}$ for experiments. 2-cell stage wild-type zen-4::gfp (SM2233) and div-1 (EU548) embryos were picked and aged for 1 hour on the same poly-L-lysine slide in a humidity chamber at $26^{\circ} \mathrm{C}$. H3K9me2 staining after embryonic temperature shifts compared 25-30 cell wild-type embryos to $10-15$ cell div-1 embryos.

Temperature shifts to $26^{\circ} \mathrm{C}$ that started with $\mathrm{L} 4$ animals instead of embryos produced identical results in terms of H3K9me2 levels at given embryonic stages. In L4-shift experiments, mixed stage SM2233 and EU548 embryos were dissected from gravid adults and stained for $\mathrm{H} 3 \mathrm{~K} 9 \mathrm{me} 2$ on the same slide. Cells that contained the same number of cells were compared using L4-shifts.

For atl-1 rescue experiments, N2 L4s were fed with atl-1 RNAi bacteria. div-1(or148ts) L4s were fed with either empty vector or atl-1 RNAi bacteria overnight at $26^{\circ} \mathrm{C} . \mathrm{SM} 2233$ L4s were fed with bacteria containing an empty vector at $26^{\circ} \mathrm{C}$ and included as an on- 
slide control on all experiments. Embryos were dissected from gravid adults and stained for H3K9me2.

CFCA. Cell Fate Challenge Assay was conducted similarly to (Kiefer et. al, 2007). In brief, two-cell embryos were collected from wild-type, set-25 or met-2 mothers carrying an integrated HS::hlh-1 array (Fukushige and Krause, 2005). Embryos were incubated at $20^{\circ} \mathrm{C}$ for 3 hours until they reached the 100 -cell stage, determined by DAPI staining and cell counts. Heat shock was administered at $33^{\circ} \mathrm{C}$ for 30 minutes on Poly-L-Lysine slides in a humidity chamber and embryos were incubated at $20^{\circ} \mathrm{C}$ for 20 hours. Terminally differentiated embryos were stained for paramyosin (muscle, (Fukushige and Krause, 2005)) and PHA-4 (foregut, (Horner et al., 1998)). Embryos were imaged using the Zeiss LSM 700 confocal microscope. RNA expression analysis for hlh-1 was done as described previously (Mutlu et al., 2018).

GO Term Analysis. H3K9me1 (GSE49744), H3K9me2 (GSE49736) and H3K9me3 (GSE49732) methylated regions were defined by a MACS2 broad peak call (Zhang et al., 2008) and the center of peaks were assigned to genes to curate a list. DAVID (https://david.ncifcrf.gov/) was used for GO Term analysis.

Acknowledgements. We thank the Harvard Center for Biological Imaging, K. Nguyen and B. Raja for their help on TEM procedures. We acknowledge support from the NIH (R37GM056264), the John D. and Catherine T. MacArthur Foundation and Harvard University to SEM, the AAUW International Fellowship to BM. Some strains were provided by the Caenorhabditis Genetics Center, funded by NIH P400D010440. All data needed to evaluate conclusions in the paper are present in the paper and the Supplementary 
Materials. Additional data available from authors upon request. Reagents can be provided by Susan Mango pending scientific review and a completed material transfer agreement.

Author contributions. BM and SEM designed and conducted the study and wrote the manuscript. DHH performed TEM. HMC performed GO Term analysis for H3K9me. Authors have no competing interests.

\section{REFERENCES}

Ancelin, K., Lange, U. C., Hajkova, P., Schneider, R., Bannister, A. J., Kouzarides, T. and Surani, M. A. (2006). Blimp1 associates with Prmt5 and directs histone arginine methylation in mouse germ cells. Nat. Cell Biol. 8, 623-630.

Andersen, E. C. and Horvitz, H. R. (2007). Two C. elegans histone methyltransferases repress lin-3 EGF transcription to inhibit vulval development. Development 134, 2991-9.

Ashe, A., Sapetschnig, A., Weick, E.-M., Mitchell, J., Bagijn, M. P., Cording, A. C., Doebley, A.-L., Goldstein, L. D., Lehrbach, N. J., Le Pen, J., et al. (2012). piRNAs can trigger a multigenerational epigenetic memory in the germline of $\mathrm{C}$. elegans. Cell 150, 88-99.

Ayrapetov, M. K., Gursoy-Yuzugullu, O., Xu, C., Xu, Y. and Price, B. D. (2014). DNA double-strand breaks promote methylation of histone $\mathrm{H} 3$ on lysine 9 and transient formation of repressive chromatin. Proc. Natl. Acad. Sci. U. S. A. 111, 9169-74.

Basavapathruni, A., Gureasko, J., Porter Scott, M., Hermans, W., Godbole, A., Leland, P. A., Boriack-Sjodin, P. A., Wigle, T. J., Copeland, R. A. and Riera, T. V. (2016). Characterization of the Enzymatic Activity of SETDB1 and Its 1:1 Complex with ATF7IP. Biochemistry 55, 1645-1651.

Baugh, L. R. (2003). Composition and dynamics of the Caenorhabditis elegans early embryonic transcriptome. Development 130, 889-900.

Becker, J. S., Nicetto, D. and Zaret, K. S. (2015). H3K9me3-Dependent Heterochromatin: Barrier to Cell Fate Changes. Trends Genet.

Blythe, S. A. and Wieschaus, E. F. (2016). Establishment and maintenance of heritable chromatin structure during early Drosophila embryogenesis. Elife 5,.

Bowman, E., Seydoux, G. and Kelly, W. (2011). Temperature sensitive mutants of the RNA polymerase II TFIID initiation factor, taf-6.2. Worm Breeder's Gaz. 
Brauchle, M., Baumer, K. and Gönczy, P. (2003). Differential activation of the DNA replication checkpoint contributes to asynchrony of cell division in C. elegans embryos. Curr. Biol. 13, 819-27.

Bregman, D. B., Du, L., Van Der Zee, S. and Warren, S. L. (1995). Transcriptiondependent redistribution of the large subunit of RNA polymerase II to discrete nuclear domains. J. Cell Biol.

Brenner, S. (1974). The genetics of Caenorhabditis elegans. Genetics 77, 71-94.

Bühler, M. and Moazed, D. (2007). Transcription and RNAi in heterochromatic gene silencing. Nat. Struct. Mol. Biol. 14, 1041-1048.

Burkhart, K. B., Guang, S., Buckley, B. A., Wong, L., Bochner, A. F. and Kennedy, S. (2011). A Pre-mRNA-Associating Factor Links Endogenous siRNAs to Chromatin Regulation. PLoS Genet. 7, e1002249.

Burton, N. O., Burkhart, K. B. and Kennedy, S. (2011). Nuclear RNAi maintains heritable gene silencing in Caenorhabditis elegans. Proc. Natl. Acad. Sci. U. S. A. 108, 19683-8.

Dekens, M. P. S., Pelegri, F. J., Maischein, H.-M. and Nüsslein-Volhard, C. (2003). The maternal-effect gene futile cycle is essential for pronuclear congression and mitotic spindle assembly in the zebrafish zygote. Development 130, 3907-16.

Detwiler, M. R., Reuben, M., Li, X., Rogers, E. and Lin, R. (2001). Two Zinc Finger Proteins, OMA-1 and OMA-2, Are Redundantly Required for Oocyte Maturation in C. elegans. Dev. Cell 1, 187-199.

Djabrayan, N. J.-V., Dudley, N. R., Sommermann, E. M. and Rothman, J. H. (2012). Essential role for Notch signaling in restricting developmental plasticity. Genes Dev. 26, 2386-91.

Edgar, L. G., Wolf, N. and Wood, W. B. (1994). Early transcription in Caenorhabditis elegans embryos. Development 120, 443-51.

Encalada, S. E., Martin, P. R., Phillips, J. B., Lyczak, R., Hamill, D. R., Swan, K. A. and Bowerman, B. (2000). DNA replication defects delay cell division and disrupt cell polarity in early Caenorhabditis elegans embryos. Dev. Biol. 228, 225-38.

Ferree, P. L., Deneke, V. E. and Di Talia, S. (2016). Measuring time during early embryonic development. Semin. Cell Dev. Biol. 55, 80-8.

Fukushige, T. and Krause, M. (2005). The myogenic potency of HLH-1 reveals widespread developmental plasticity in early C. elegans embryos. Development 132, 1795-805.

Garrigues, J., Sidoli, S., Garcia, B. and Strome, S. (2014). Defining heterochromatin in $\mathrm{C}$. elegans through genome-wide analysis of the heterochromatin protein 1 homolog HPL-2. Genome Res. 1-14.

Gaspar-Maia, A., Alajem, A., Polesso, F., Sridharan, R., Mason, M. J., Heidersbach, 
A., Ramalho-Santos, J., McManus, M. T., Plath, K., Meshorer, E., et al. (2009). Chd1 regulates open chromatin and pluripotency of embryonic stem cells. Nature 460, 863-8.

Gaspar-Maia, A., Alajem, A., Meshorer, E. and Ramalho-Santos, M. (2011). Open chromatin in pluripotency and reprogramming. Nat. Rev. Mol. Cell Biol. 12, 36-47.

Gilleard, J. S. and McGhee, J. D. (2001). Activation of hypodermal differentiation in the Caenorhabditis elegans embryo by GATA transcription factors ELT-1 and ELT-3. Mol. Cell. Biol. 21, 2533-2544.

Gu, W., Shirayama, M., Conte, D., Vasale, J., Batista, P. J., Claycomb, J. M., Moresco, J. J., Youngman, E. M., Keys, J., Stoltz, M. J., et al. (2009). Distinct Argonaute-Mediated 22G-RNA Pathways Direct Genome Surveillance in the C. elegans Germline. Mol. Cell 36, 231-244.

Gu, S. G., Pak, J., Guang, S., Maniar, J. M., Kennedy, S. and Fire, A. (2012). Amplification of siRNA in Caenorhabditis elegans generates a transgenerational sequence-targeted histone H3 lysine 9 methylation footprint. Nat. Genet. 44, 157164.

Guang, S., Bochner, A. F., Pavelec, D. M., Burkhart, K. B., Harding, S., Lachowiec, J. and Kennedy, S. (2008). An Argonaute transports siRNAs from the cytoplasm to the nucleus. Science 321, 537-41.

Guang, S., Bochner, A. F., Burkhart, K. B., Burton, N., Pavelec, D. M. and Kennedy, S. (2010). Small regulatory RNAs inhibit RNA polymerase II during the elongation phase of transcription. Nature 465, 1097-1101.

Guven-Ozkan, T., Nishi, Y., Robertson, S. M. and Lin, R. (2008). Global Transcriptional Repression in C. elegans Germline Precursors by Regulated Sequestration of TAF-4. Cell 135, 149-160.

Hisahara, S., Chiba, S., Matsumoto, H., Tanno, M., Yagi, H., Shimohama, S., Sato, M. and Horio, Y. (2008). Histone deacetylase SIRT1 modulates neuronal differentiation by its nuclear translocation. Proc. Natl. Acad. Sci. U. S. A. 105, 15599-604.

Hontelez, S., van Kruijsbergen, I., Georgiou, G., van Heeringen, S. J., Bogdanovic, O., Lister, R. and Veenstra, G. J. C. (2015). Embryonic transcription is controlled by maternally defined chromatin state. Nat. Commun. 6, 10148.

Horner, M. A., Quintin, S., Domeier, M. E., Kimble, J., Labouesse, M. and Mango, S. E. (1998). pha-4, an HNF-3 homolog, specifies pharyngeal organ identity in Caenorhabditis elegans. Genes Dev. 12, 1947-52.

Howe, J. A. and Newport, J. W. (1996). A developmental timer regulates degradation of cyclin $\mathrm{E} 1$ at the midblastula transition during Xenopus embryogenesis. Proc. Natl. Acad. Sci. U. S. A. 93, 2060-4.

Hsu, H.-T., Chen, H.-M., Yang, Z., Wang, J., Lee, N. K., Burger, A., Zaret, K., Liu, T., Levine, E. and Mango, S. E. (2015). Recruitment of RNA polymerase II by the 
pioneer transcription factor PHA-4. Science (80-. ). 348, 1372-1376.

Hug, C. B., Grimaldi, A. G., Kruse, K. and Vaquerizas, J. M. (2017). Chromatin Architecture Emerges during Zygotic Genome Activation Independent of Transcription. Cell 169, 216-228.e19.

Jiao, A. L., Foster, D. J., Dixon, J. and Slack, F. J. (2018). lin-4 and the NRDE pathway are required to activate a transgenic lin- 4 reporter but not the endogenous lin-4 locus in C. elegans. PLoS One.

Jih, G., Iglesias, N., Currie, M. A., Bhanu, N. V., Paulo, J. A., Gygi, S. P., Garcia, B. A. and Moazed, D. (2017). Unique roles for histone H3K9me states in RNAi and heritable silencing of transcription. Nature 547, 463-467.

Joshi, P. M., Riddle, M. R., Djabrayan, N. J. V and Rothman, J. H. (2010). Caenorhabditis elegans as a model for stem cell biology. Dev. Dyn. 239, 1539-54.

Kaltenbach, L., Horner, M. A., Rothman, J. H. and Mango, S. E. (2000). The TBP-like Factor CeTLF Is Required to Activate RNA Polymerase II Transcription during C. elegans Embryogenesis. Mol. Cell 6, 705-713.

Kaltenbach, L. S., Updike, D. L. and Mango, S. E. (2005). Contribution of the amino and carboxyl termini for PHA-4/FoxA function in Caenorhabditis elegans. Dev. Dyn. 234, 346-54.

Kang, Y.-K. (2014). SETDB1 in Early Embryos and Embryonic Stem Cells. Curr. Issues Mol. Biol. 17, 1-10.

Kimelman, D., Kirschner, M. and Scherson, T. (1987). The events of the midblastula transition in Xenopus are regulated by changes in the cell cycle. Cell 48, 399-407.

Kleine-Kohlbrecher, D., Christensen, J., Vandamme, J., Abarrategui, I., Bak, M., Tommerup, N., Shi, X., Gozani, O., Rappsilber, J., Salcini, A. E., et al. (2010). A functional link between the histone demethylase PHF8 and the transcription factor ZNF711 in X-linked mental retardation. Mol. Cell 38, 165-78.

Larson, A. G., Elnatan, D., Keenen, M. M., Trnka, M. J., Johnston, J. B., Burlingame, A. L., Agard, D. A., Redding, S. and Narlikar, G. J. (2017). Liquid droplet formation by HP1a suggests a role for phase separation in heterochromatin. Nature 547, 236-240.

Levin, M., Hashimshony, T., Wagner, F. and Yanai, I. (2012). Developmental milestones punctuate gene expression in the Caenorhabditis embryo. Dev. Cell 22, 1101-8.

Loyola, A., Tagami, H., Bonaldi, T., Roche, D., Quivy, J. P., Imhof, A., Nakatani, Y., Dent, S. Y. R. and Almouzni, G. (2009). The HP1alpha-CAF1-SetDB1-containing complex provides $\mathrm{H} 3 \mathrm{~K} 9 \mathrm{me} 1$ for Suv39-mediated $\mathrm{K} 9 \mathrm{me} 3$ in pericentric heterochromatin. EMBO Rep. 10, 769-75.

Mango, S. E. (2007). A green light to expression in time and space. Nat. Biotechnol. 25, 645-646. 
Mango, S. E. (2009). The molecular basis of organ formation: insights from the C. elegans foregut. Annu. Rev. Cell Dev. Biol. 25, 597-628.

McMurchy, A. N., Stempor, P., Gaarenstroom, T., Wysolmerski, B., Dong, Y., Aussianikava, D., Appert, A., Huang, N., Kolasinska-Zwierz, P., Sapetschnig, A., et al. (2017). A team of heterochromatin factors collaborates with small RNA pathways to combat repetitive elements and germline stress. Elife 6, e21666.

Meier, M., Grant, J., Dowdle, A., Thomas, A., Gerton, J., Collas, P., O’Sullivan, J. M. and Horsfield, J. A. (2018). Cohesin facilitates zygotic genome activation in zebrafish. Development 145, dev.156521.

Moazed, D. (2009). Small RNAs in transcriptional gene silencing and genome defence. Nature 457, 413-420.

Mutlu, B., Chen, H.-M., Moresco, J. J., Orelo, B. D., Yang, B., Gaspar, J. M., Keppler-Ross, S., Yates, J. R., Hall, D. H., Maine, E. M., et al. (2018). Regulated nuclear accumulation of a histone methyltransferase times the onset of heterochromatin formation in C. elegans embryos. Sci. Adv. 4, eaat6224.

Myers, T. R., Amendola, P. G., Lussi, Y. C. and Salcini, A. E. (2018). JMJD-1.2 controls multiple histone post-translational modifications in germ cells and protects the genome from replication stress. Sci. Rep. 8, 3765.

Newport, J. and Kirschner, M. (1982a). A major developmental transition in early Xenopus embryos: II. Control of the onset of transcription. Cell 30, 687-96.

Newport, J. and Kirschner, M. (1982b). A major developmental transition in early Xenopus embryos: I. characterization and timing of cellular changes at the midblastula stage. Cell 30, 675-86.

Ni, J. Z., Chen, E. and Gu, S. G. (2014). Complex coding of endogenous siRNA, transcriptional silencing and $\mathrm{H} 3 \mathrm{~K} 9$ methylation on native targets of germline nuclear RNAi in C. elegans. BMC Genomics 15, 1157.

Niwa, H. (2007). How is pluripotency determined and maintained? Development 134, 635-46.

Norris, A. D., Kim, H.-M., Colaiácovo, M. P. and Calarco, J. A. (2015). Efficient Genome Editing in Caenorhabditis elegans with a Toolkit of Dual-Marker Selection Cassettes. Genetics 201, 449-58.

Østrup, O., Andersen, I. S. and Collas, P. (2013). Chromatin-linked determinants of zygotic genome activation. Cell. Mol. Life Sci. 70, 1425-1437.

Pak, J. and Fire, A. (2007). Distinct Populations of Primary and Secondary Effectors During RNAi in C. elegans. Science (80-. ). 315, 241-244.

Penke, T. J. R., McKay, D. J., Strahl, B. D., Matera, A. G. and Duronio, R. J. (2016). Direct interrogation of the role of $\mathrm{H} 3 \mathrm{~K} 9$ in metazoan heterochromatin function. Genes Dev. 30, 1866-80. 
Politz, J. C. R., Scalzo, D. and Groudine, M. (2013). Something silent this way forms: the functional organization of the repressive nuclear compartment. Annu. Rev. Cell Dev. Biol. 29, 241-70.

Poulin, G., Dong, Y., Fraser, A. G., Hopper, N. A. and Ahringer, J. (2005). Chromatin regulation and sumoylation in the inhibition of Ras-induced vulval development in Caenorhabditis elegans. EMBO J. 24, 2613-23.

Priess, J. R. and Thomson, J. N. (1987). Cellular interactions in early C. elegans embryos. Cell 48, 241-250.

Pritchard, D. K. and Schubiger, G. (1996). Activation of transcription in Drosophila embryos is a gradual process mediated by the nucleocytoplasmic ratio. Genes Dev. 10, 1131-42.

Robertson, S. M., Shetty, P. and Lin, R. (2004). Identification of lineage-specific zygotic transcripts in early Caenorhabditis elegans embryos. Dev. Biol. 276, 493507.

Rübe, C. E., Lorat, Y., Schuler, N., Schanz, S., Wennemuth, G. and Rübe, C. (2011). DNA repair in the context of chromatin: New molecular insights by the nanoscale detection of DNA repair complexes using transmission electron microscopy. DNA Repair (Amst). 10, 427-437.

Schauer, I. and Wood, W. (1990). Early C. elegans embryos are transcriptionally active. Development 110, 1303-1317.

Seydoux, G. and Dunn, M. A. (1997). Transcriptionally repressed germ cells lack a subpopulation of phosphorylated RNA polymerase II in early embryos of Caenorhabditis elegans and Drosophila melanogaster. Development.

Seydoux, G. and Fire, A. (1994). Soma-germline asymmetry in the distributions of embryonic RNAs in Caenorhabditis elegans. Development 120, 2823-2834.

Soufi, A., Donahue, G. and Zaret, K. S. (2012). Facilitators and impediments of the pluripotency reprogramming factors' initial engagement with the genome. Cell 151, 994-1004.

Storfer-Glazer, F. A. and Wood, W. B. (1994). Effects of chromosomal deficiencies on early cleavage patterning and terminal phenotype in Caenorhabditis elegans embryos. Genetics 137, 499-508.

Strom, A. R., Emelyanov, A. V., Mir, M., Fyodorov, D. V., Darzacq, X. and Karpen, G. H. (2017). Phase separation drives heterochromatin domain formation. Nature 547, 241-245.

Sulston, J. E., Schierenberg, E., White, J. G. and Thomson, J. N. (1983). The embryonic cell lineage of the nematode Caenorhabditis elegans. Dev. Biol. 100, 64-119.

Tintori, S. C., Osborne Nishimura, E., Golden, P., Lieb, J. D. and Goldstein, B. (2016). A Transcriptional Lineage of the Early C. elegans Embryo. Dev. Cell 38, 
430-444.

Towbin, B. D., González-Aguilera, C., Sack, R., Gaidatzis, D., Kalck, V., Meister, P., Askjaer, P. and Gasser, S. M. (2012). Step-wise methylation of histone H3K9 positions heterochromatin at the nuclear periphery. Cell 150, 934-47.

Treen, N., Heist, T., Wang, W. and Levine, M. (2018). Depletion of Maternal Cyclin B3 Contributes to Zygotic Genome Activation in the Ciona Embryo. Curr. Biol.

Wang, G. and Reinke, V. (2008). A C. elegans Piwi, PRG-1, regulates 21U-RNAs during spermatogenesis. Curr. Biol. 18, 861-7.

Wang, J. T. and Seydoux, G. (2014). P granules. Curr. Biol. 24, R637-R638.

Wang, H., An, W., Cao, R., Xia, L., Erdjument-Bromage, H., Chatton, B., Tempst, P., Roeder, R. G. and Zhang, Y. (2003). mAM facilitates conversion by ESET of dimethyl to trimethyl lysine 9 of histone $\mathrm{H} 3$ to cause transcriptional repression. Mol. Cell 12, 475-487.

Weick, E.-M. and Miska, E. A. (2014). piRNAs: from biogenesis to function. Development 141, 3458-71.

Wood, W. B. (1991). Evidence from reversal of handedness in C. elegans embryos for early cell interactions determining cell fates. Nature 349, 536-538.

Yigit, E., Batista, P. J., Bei, Y., Pang, K. M., Chen, C.-C. G., Tolia, N. H., JoshuaTor, L., Mitani, S., Simard, M. J. and Mello, C. C. (2006). Analysis of the C. elegans Argonaute Family Reveals that Distinct Argonautes Act Sequentially during RNAi. Cell 127, 747-757.

Yu, R., Jih, G., Iglesias, N. and Moazed, D. (2013). Determinants of Heterochromatic siRNA Biogenesis and Function. Mol. Cell.

Yuan, K., Seller, C. A., Shermoen, A. W. and O'Farrell, P. H. (2016). Timing the Drosophila Mid-Blastula Transition: A Cell Cycle-Centered View. Trends Genet. 32 , 496-507.

Yuzyuk, T., Fakhouri, T. H. I., Kiefer, J. and Mango, S. E. (2009). The polycomb complex protein mes-2/E(z) promotes the transition from developmental plasticity to differentiation in C. elegans embryos. Dev. Cell 16, 699-710.

Zaret, K. S. and Mango, S. E. (2016). Pioneer transcription factors, chromatin dynamics, and cell fate control. Curr. Opin. Genet. Dev. 37, 76-81.

Zeller, P., Padeken, J., van Schendel, R., Kalck, V., Tijsterman, M. and Gasser, S. M. (2016). Histone H3K9 methylation is dispensable for Caenorhabditis elegans development but suppresses RNA:DNA hybrid-associated repeat instability. Nat. Genet. 48, 1385-1395.

Zhang, Y., Liu, T., Meyer, C. A., Eeckhoute, J., Johnson, D. S., Bernstein, B. E., Nusbaum, C., Myers, R. M., Brown, M., Li, W., et al. (2008). Model-based analysis of ChIP-Seq (MACS). Genome Biol. 9, R137. 
Zhu, J., Fukushige, T., McGhee, J. D. and Rothman, J. H. (1998). Reprogramming of early embryonic blastomeres into endodermal progenitors by a Caenorhabditis elegans GATA factor. Genes Dev. 12, 3809-3814. 